\title{
MONOLITHIC CENTRIFUGAL MICROFLUIDIC PLATFORM FOR BACTERIA CAPTURE AND CONCENTRATION, LYSIS, NUCLEIC-ACID AMPLIFICATION, AND REAL-TIME DETECTION
}

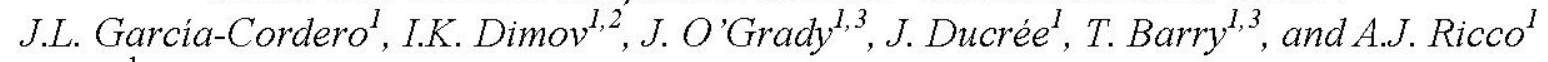

${ }^{1}$ Biomedical Diagnostics Institute, Dublin City University, Dublin, IRELAND

${ }^{2}$ Department of Biomedical Engineering, Universidad de Valparaiso, CHILE

${ }^{3}$ Biomedical Diagnostics Institute Programme, National Centre for Biomedical Engineering Science, National University of Ireland, Galway, IRELAND

\begin{abstract}
We report the design, fabrication, and characterization of a polymer centrifugal microfluidic system for the specific detection of bacterial pathogens. This single-cartridge platform integrates bacteria capture and concentration, supernatant solution removal, lysis, and nucleic-acid sequence-based amplification (NASBA) in a single unit. The unit is fabricated using multilayer lamination and consists of five different polymer layers. Bacteria capture and concentration are accomplished by sedimentation in five minutes. Centrifugation forces also drive the subsequent steps. A wax valve is integrated in the cartridge to enable high-speed centrifugation. Oil is used to prevent evaporation during reactions requiring thermal cycling. Device functionality was demonstrated by real-time detection of $E$. coli from a $200-\mu \mathrm{L}$ sample.
\end{abstract}

\section{INTRODUCTION}

Rapid detection and precise identification of bacterial pathogens is critical in food and water monitoring and in clinical diagnostics $[1,2]$. Detection becomes more challenging because of the low concentration of pathogens $(10-100)$ in large-volume samples [2]. Traditional techniques such as visual microscopy, plating, or culture enrichment can require times in the order of days, require access to unique facilities (bio-hazard containment), and need skilled technicians who may have to perform many repetitive steps.

Detection assays based on nucleic acid amplification methods have made possible the precise identification of low numbers of pathogens in relative short periods of time (tens of minutes to hours) [3]. However, compared to traditional methods, there are more process steps involved to achieve sensitive detection of pathogens, such as lysis of the organism and in some cases nucleic acid purification. Also, reagents (lysis buffer, primers, and enzymes) are needed to conduct these reactions. Sample concentration may be required for the assay to be most effective and to reduce reagent consumption. In addition, processing involves manual handling, expensive instrumentation, and liquid transfer to different containers, which can reduce the limits of detection or lead to false positives. Thus, there is a need for an automated platform that integrates the different steps involved in nucleic-acid amplification-based assays.

Microfluidics and lab-on-a-chip (LOC) technologies are enabling the integration and automation of sophisticated diagnostic tests, traditionally carried out in clinical laboratories, into nearly-autonomous monolithic systems the size of a microscope slide or a credit card [2, 4-13]. These devices offer reductions in reagent and sample volumes, as well as shorter assay times.

Several microfluidic devices have been reported for the detection of bacteria [4-10] and viruses [11-14]. Magnetic microbeads coated with specific antibodies against the target organism are one popular technique to capture, isolate, and concentrate pathogens [4-13]. However, this technique adds costs to the assay because specific antibodies are needed for each target organism. Dielectrophoresis is another technique used to capture and concentrate bacteria; however, it has low throughput because low flow rates are needed to efficiently capture bacteria [6-7].

Operation of these devices requires the combination of electrophoretic and thermopneumatic pumps [4], whereas other microdevices require expensive syringe pumps and pneumatic lines to move liquids through the device [5-7, 10-12]. Centrifugal microfluidics offers inherent advantages over these and other microfluidic pumping and actuation mechanisms: it can pump liquids in a wide range of flow rates, mixing can be easily accomplished by alternating the direction of rotation, and valving can be implemented by carefully controlling the rotation speed [14].

Centrifugation is widely utilized in many laboratories to capture and isolate bacteria. Because most bacteria have a higher density than the media in which they are suspended, they can be sedimented and thus concentrated and captured. Our device uses similar principles, combining the advantages of centrifugal microfluidics to control liquid transportation and to implement liquid metering. Our monolithic system executes two basic operations: bacteria are sedimented in a container and concentrated; successive reaction steps (lysis, sample conditioning, and NASBA) that otherwise would require manual pipetting are integrated on the disc using a microfluidic channel that allows removal of unneeded materials.

\section{DESIGN AND FABRICATION Design}

The design of the centrifugal microfluidic cartridge is shown in Figure 1. The device consists of a main chamber in the form of a funnel that holds a sample of $200 \mu \mathrm{L}$ (scalable to hold larger volumes). The bottom of the funnel features a rectangular-shaped vessel where the various reactions are carried out. The volume of this vessel is $5 \mu \mathrm{L}$, and as with the funnel, it can also be scaled with corresponding scaling of reagent consumption. A 5-cm-long microfluidic channel connects the waste chamber to the main funnel-shaped chamber; its purpose is to remove reactants not needed and to define the vessel 
volume. The entrance to the microfluidic channel is initially sealed with wax. The waste chamber holds 100 $\mu \mathrm{L}$ more volume than the main chamber, which is needed for the subsequent steps where other reagents are loaded into the cartridge. The waste chamber features a hole that functions as a vent, equalizing it with atmospheric pressure. Alignment holes are included on each layer to facilitate alignment.

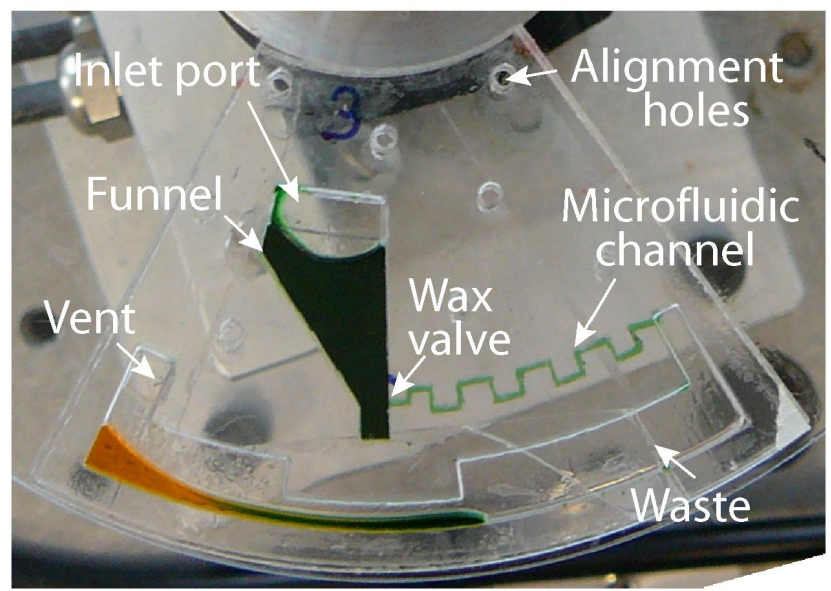

Figure 1: Centrifugal cartridge for the detection and analysis of bacteria.

\section{Fabrication}

Devices were fabricated using multi-layer lamination as shown in Figure 2. $\mathrm{A} \mathrm{CO}_{2}$ laser system (Laser Micromachining LightDeck, Optec, Belgium) was used to cut the polymer layers. To laminate the layers, a thermal roller (Titan-110, GBC Films, USA) was used. The funnel structure and waste camber were cut from a 1.2$\mathrm{mm}$ thick poly(methylmethacrylate) sheet (GoodFellow, UK) previously laminated with an $80-\mu \mathrm{m}$ thick layer of pressure-sensitive adhesive, PSA (AR9808, Adhesives Research, Ireland). The microfluidic channel, cut from the same PSA, had a measured width of approximately $400 \mu \mathrm{m}$.

All layers except the cover were carefully aligned and passed through the laminator. The valve was formed by manually loading a small amount of solid wax at the intersection of the microfluidic channel with the main chamber. The device was then warmed on a hot plate at $70{ }^{\circ} \mathrm{C}$ to melt the wax, which then filled the entrance of the channel by capillary action. Finally, the cover layer was laminated onto the device. The final assembled device was mounted on a transparent compact disc (Åmic, Sweden) using the same PSA (AR9808).

\section{MATERIALS AND METHODS}

Figure 3 presents the sequence of steps performed on the microfluidic cartridge. A brushless DC motor with an integrated optical encoder (Series 4490, Faulhaber, Switzerland) is used to rotate the disc through the various steps.

Sample is loaded in the main chamber and spun for $10 \mathrm{~min}$ at $6000 \mathrm{rpm}$ to sediment the bacteria to the bottom of the funnel, Figure 3A. Although higher speeds could decrease the sedimentation time, the adhesive layer does not withstand pressures above this speed, and the funnel would eventually rupture from the bottom. Sealing of the different layers with thermal lamination could prevent this problem.

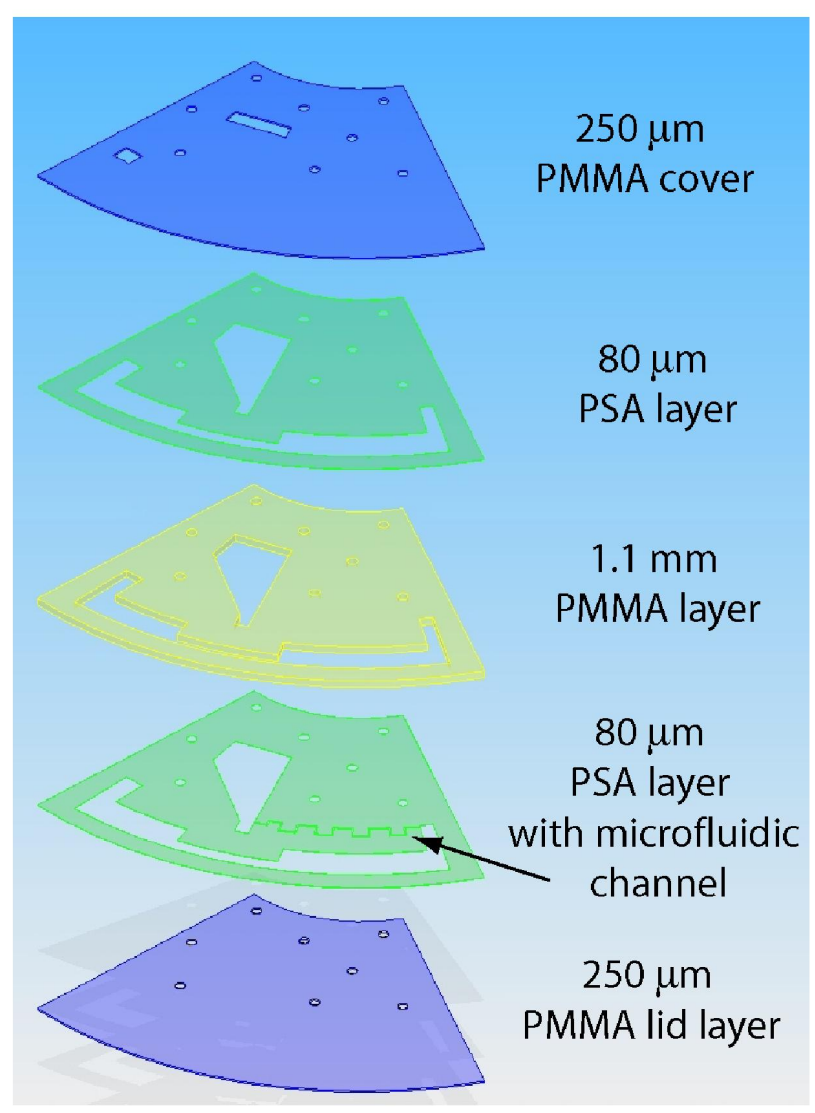

Figure 2: Five different plastic layers are used to build the centrifugal cartridge.

The disc is stopped and the wax valve opened by heating it to $70^{\circ} \mathrm{C}$ using a Thermofoil flexible heater (Minco, USA), Figure 3B. The disc is spun again at 700 rpm for $1 \mathrm{~min}$ to discharge the supernatant solution through the microfluidic channel into the waste chamber. The remaining $5 \mu \mathrm{L}$ of liquid in the vessel includes a "pellet" that contains most of the bacteria, Figure 3C. Platform capture efficiency is characterized by applying different concentrations of $E$. coli, genetically modified to express green fluorescent protein (GFP), and assaying the captured bacteria by fluorescence.

Next, $10 \mu \mathrm{L}$ of oil is introduced through the inlet port as shown in Figure 3D. The disc is spun and the oil covers the contents of the reaction vessel and also seals the microfluidic channel, preventing any evaporation during the various reactions steps.

Next, $20 \mu \mathrm{L}$ of chemical lysis solution (microLysis Plus, Microzone, UK) are introduced through the inlet and, by spinning, the lysis reagent sinks and mixes with the bacteria pellet, Figure $3 \mathrm{E}$. This mixture is thermally cycled as per the manufacturer's instructions $\left(65^{\circ} \mathrm{C}: 15\right.$ $\min , 96^{\circ} \mathrm{C}: 2 \mathrm{~min}, 65^{\circ} \mathrm{C}: 4 \mathrm{~min}, 96^{\circ} \mathrm{C}: 1 \mathrm{~min}, 65^{\circ} \mathrm{C}: 1 \mathrm{~min}$, $96^{\circ} \mathrm{C}: 30 \mathrm{sec}$ ) to lyse the bacteria, releasing nucleic acids including the RNA target. Thermal cycling also continuously mixes both solutions, Figure $3 \mathrm{~F}$. 


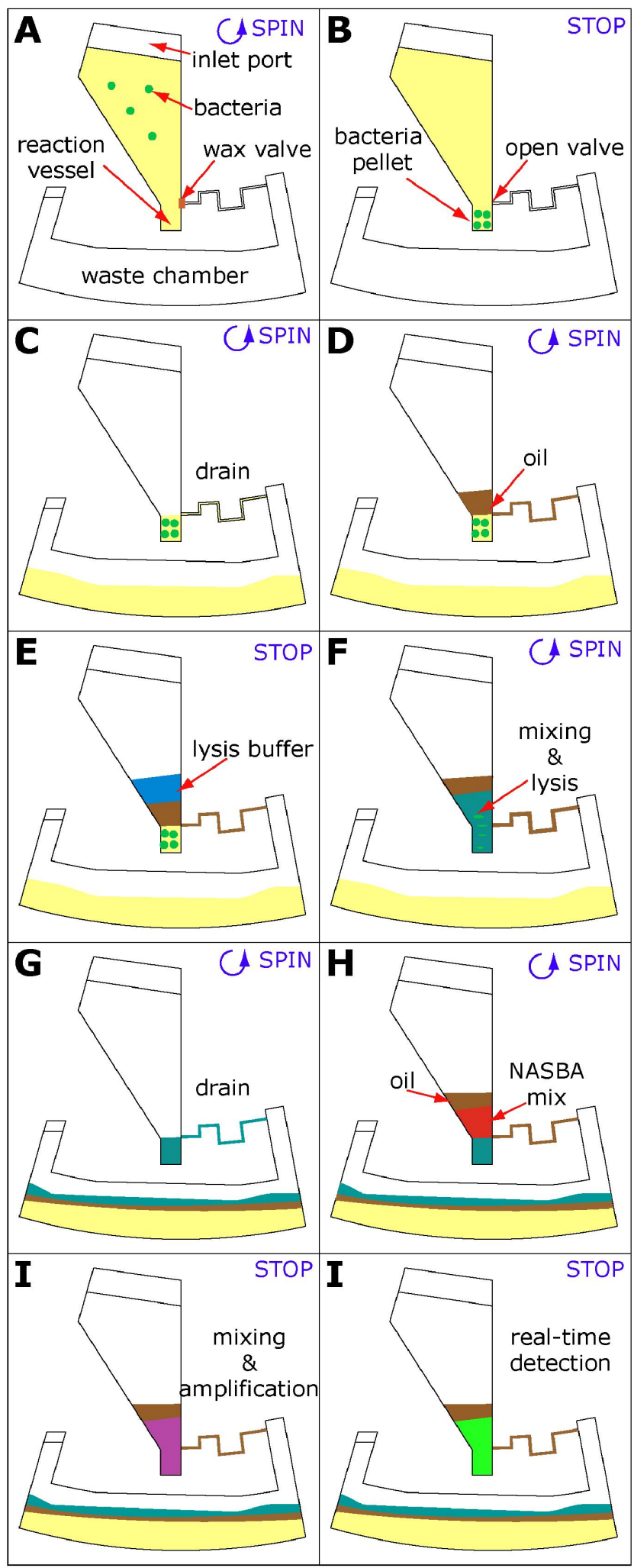

Figure 3: Steps involved in the detection of bacteria in the centrifugal microfluidic platform. See texts for details.

The disc is spun again, and some of the lysate goes into the waste, but $5 \mu \mathrm{L}$ of the lysate remain in the vessel. The lysate is covered by a fresh layer of oil, and $5 \mu \mathrm{L}$ of NASBA enzymes are introduced into the compartment by spinning and allowed to react with the lysate for $5 \mathrm{~min}$ at $61^{\circ} \mathrm{C}$. Finally, $15 \mu \mathrm{L}$ of NASBA mixture, including primers and molecular beacons for the target bacterial tmRNA fragment, are loaded into the platform and the solution incubated at $41^{\circ} \mathrm{C}$. Detection of amplified
tmRNA target is in real-time via molecular beacons whose fluorescence is unquenched when hybridized to complementary RNA amplicons [15-16]. Figure 5 shows the NASBA-based detection of $E$. coli on this platform.

\section{RESULTS AND DISCUSSION}

Concentrations of GFP E. coli ranging from $10^{1}-10^{8}$ $\mathrm{cfu} / \mathrm{mL}$ were prepared. Then, $100 \mu \mathrm{L}$ of each concentration were loaded into a microwell plate. The plate was read with a fluorescent plate reader (Infinite 200, Tecan, USA), revealing a linear correlation of fluorescent intensity to bacteria concentration from $10^{4}-$ $10^{8}$ bacteria $/ \mathrm{mL}$. These data enabled characterization of the bacteria capture efficiency of the funnel.

The density of $E$. coli is $1.088 \mathrm{~g} / \mathrm{cm}^{3}$, while that of the sample buffer was $\sim 1.022 \mathrm{~g} / \mathrm{cm}^{3}$. This difference allows the sedimentation and concentration of bacteria. Microfluidic units were loaded with different concentrations, valves opened, and supernatant discarded into the waste chamber. $100 \mu \mathrm{L}$ of supernatant were extracted from the waste chamber with a pipette, loaded into the microwell plate, and read with the fluorescent scanner.

To calculate the capture percentage efficiency of the devices, the supernatant concentration was subtracted from the initial concentration and divided by 100 . Typically, more than $80 \%$ of the cells were captured in the compartment, as shown in Table 1. Experiments were repeated in triplicate. Figure 4 shows bacteria captured on one of the funnel from a solution containing $10^{8} \mathrm{GFP}$ E.coli $/ \mathrm{mL}$.

Table 1: Bacteria capture efficiency of the centrifugal microfluidic platform.

\begin{tabular}{|c|c|c|}
\hline $\begin{array}{c}\text { Initial } \\
\text { Concentration } \\
(\mathrm{ml})\end{array}$ & $\begin{array}{c}\text { Supernatant } \\
\text { Concentration } \\
(\mathrm{ml})\end{array}$ & $\begin{array}{c}\text { Capture } \\
\text { percentage } \\
(\%)\end{array}$ \\
\hline $10^{8}$ & $1.4 \times 10^{7}$ & 85 \\
\hline $10^{7}$ & $7.5 \times 10^{5}$ & 92 \\
\hline $10^{6}$ & $1.9 \times 10^{5}$ & 80 \\
\hline
\end{tabular}

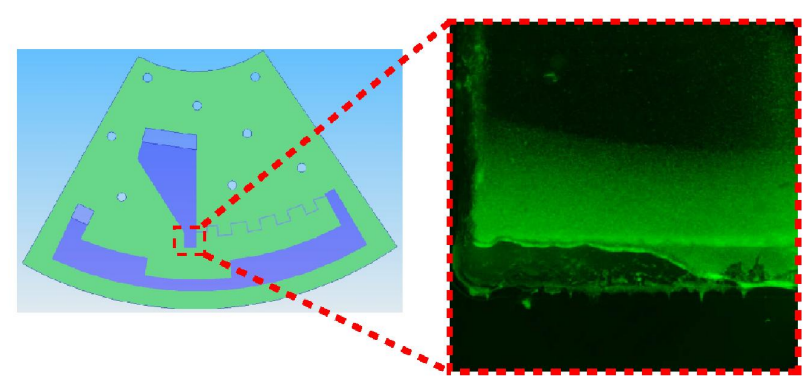

Figure 4: GFP E. coli captured at the bottom of the funnel.

The unit was characterized using water spiked with a concentration of $10^{5} \mathrm{E}$. coli $/ \mathrm{mL}$, performing all the steps described in the Methods section. Figure 5 shows the NASBA-based detection of $E$. coli on this platform. 


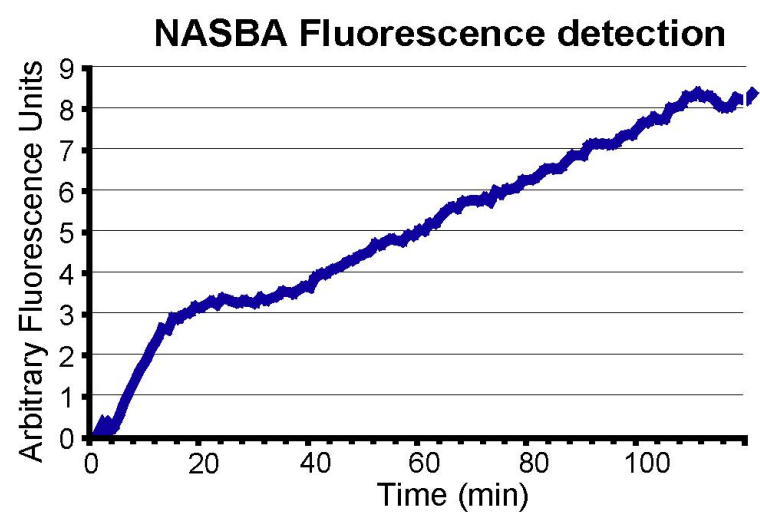

Figure 5: NASBA real-time detection of a positive sample containing $10^{5}$ bacteria per $m L$.

\section{CONCLUSIONS}

We have demonstrated that the detection of bacteria can be accomplished in a centrifugal microfluidic cartridge. We integrated sample preparation and concentration, lysis of pathogens, and nucleic acid sequence-based amplification into a monolithic polymer platform that is inexpensive to manufacture. We are working to integrate reagent storage and laser-activated valves on this platform to enable a fully automated, selfcontained unit to detect pathogenic bacteria.

\section{ACKNOWLEDGMENTS}

This work was supported by the Science Foundation Ireland under Grant No. 05/CE3/B754. We thank Majella Maher, Terry Smith, Paul Daly, and Claus Poulsen for helpful discussions and Niamh Gilmartin for providing GFP E. coli.

\section{REFERENCES}

[1] S. Bhattacharya, J. Jang, L. Yang, D. Akin, R. Bashir, "Biomems and nanotechnology-based approaches fro rapid detection of biological entities", J Rapid Met Autom Microbiol, vol 15, pp.1-32, 2007.

[2] A.K. Balasubramanian, K.A Soni, A. Beskok, S.D. Pillai, "A microfluidic device for continuous capture and concentration of microorganisms from potable water", Lab Chip, vol 7, pp. 1315-1321, 2007.

[3] L.A. Jaykus, "Challenges to developing real-time methods to detect pathogens in food", ASM News, vol 69, pp.341-347, 2003.

[4] R.H. Liu, J. Yang, R. Lenigk, J. Bonanno, P. Grodzinski, "Self-contained, fully integrated biochip for sample preparation, polymerase chain reaction amplification, and DNA microarray detection", Anal Chem, vol 7, pp.1824-1831, 2004.

[5] E.T. Lagally, J.R. Scherer, R.G. Blazej, N.M. Toriello, B.A. Diep, M. Ramchandani, G.F. Sensabaugh, L.W. Riley, R.A. Mathies, "Integrated portable genetic analysis microsystem for pathogen/infectious disease detection", Anal Chem, vol. 76, pp. 3162-3170, 2004

[6] E.T. Lagally, S. Lee, H.T. Soh, "Integrated microsystem for dielectrophoretic cell concentration and genetic detection", Lab Chip, vol 5, pp.10531058,2005
[7] B.H. Lapizco-Encinas, B. A. Simmons, E.B. Cummings, Y. Fintschenko, "Insulator-based dielectrophoresis for the selective concentration and separation of live bacteria in water", Electrophoresis, vol. 25, pp. 1695-1704, 2004

[8] C.G. Koh, W. Tan, M.Q. Zhao, A.J. Ricco, Z.H. Fan, "Integrating polymerase chain reaction, valving, and electrophoresis in a plastic device for bacterial detection", Anal Chem, vol. 75, pp. 4591-4598, 2003

[9] L.C. Waters, S.C. Jacobson, N. Kroutchinina, J. Khandurina, R.S. Foote, J.M. Ramsey, "Microchip device for cell lysis, multiplex PCR amplification, and electrophoretic sizing", Anal Chem, vol. 70, pp 158-162, 1998

[10]Z. Chen, M.G. Mauk, J. Wang, W.R. Abrams, P.L. Corstjens, R.S. Niedbala, D. Malamud, H.H. Bau, "A microfluidic system for saliva-based detection of infectious disease", Ann N Y Acad Sci, vol. 1098, pp. 429-436, 2007

[11] R. Pal, M. Yang, R. Lin, B.N. Johnson, N. Srivastava, S.Z. Razzacki, K.J. Chomistek, D.C. Heldsinger, R.M. Haque, V.M. Ugaz, P.K. Thwar, Z. Chen, K. Alfano, M.B. Yim, M. Krishnan, A.O. Fuller, R.G. Larson, D.T. Burke, M.A. Burns, "An integrated microfluidic device for influenza and other genetic analyses", Lab Chip, vol 5, pp.1024-1032, 2005.

[12]C.J. Easey, J.M. Karlinsey, J.M. Bienvenyue, L.A. Legendre, M.G Roper, S.H. Feldman, M.A. Hughes, E.L. Hewlett, T.J. Merkel, J.P. Ferrance, J.P. Landers, "A fully integrated microfluidic genetic analysis system with sample-in-answer-out capability", Proc Natl Acad Sci USA, vol 103, pp19272-19277, 2006

[13]J. Pipper, M. Inoue, L. Ng, P. Neuzil, Y. Zhang, L. Novak, "Catching bird flu in a droplet", Nat Met, vol. 13, pp. 1259-1263, 2007

[14]J. Ducrée, S. Haeberle, S. Lutz, S. Pausch, F. von Stetten, R. Zengerle, "The centrifugal microfluidic platform", J Micromech Microeng, vol. 17, pp. S103S115, 2007

[15]I. Dimov, J.L.Garcia-Cordero, J.O'Grady, C.R. Poulsen, C. Viguier, L. Kent, P. Daly, B. Lincoln, M Maher, R. O'Kennedy, T.JSmith, A.J. Ricco, L.P. Lee, "Integrated microfluidic tmRNA purification and real-time NASBA device for molecular Diagnostics", Lab Chip, in press.

[16] J. O'Grady, S. Sedano-Balbas, M. Maher, T.J Smith, T. Barry, "Real-time PCR detection of Listeria monocytogenes in enriched food samples based on the ssRNA gene, a novel diagnostic target", Food Microbiology, vol. 25, pp. 75-84, 2008 